\title{
Environmental management of coastal regions in the Caspian Sea
}

\author{
${ }^{1}$ J. Nouri; ${ }^{2 * A}$. R. Karbassi; ${ }^{1}$ S. Mirkia \\ ${ }^{1}$ Department of Environmental Management, Graduate School of the Environment and Energy, \\ Science and Research Campus, IAU, Tehran, Iran \\ ${ }^{2}$ Graduate Faculty of the Environment, University of Tehran, P. O. Box 14155-6135, Tehran, Iran
}

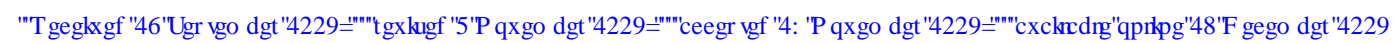

\begin{abstract}
Considering rapid population growth and migration, higher accumulation of communities is noticed in coastal areas. This is especially true with the coastal areas of the Caspian Sea. In the present investigation coastal areas between Jouybar to Behshahr region is selected for their special geographical and ecological locations. Further, adverse impacts of human, agriculture and industrial activities was examined along side the above mentioned coasts. It should be pointed out that protected Miankaleh Wildlife zone which is an internationally recognized wetland, falls within area of study. In the present study strengths, weaknesses, opportunities and threats method is used for the evaluation of environmental management status. In this regard, internal and external factors gained 2.28 and 2.58 scores. This is indicative of the abundance of weaknesses over strengths and it also shows that opportunities are more than threats. Subsequently 27 strategies were developed and quantitative strategic planning matrix method was also used to score each strategies. The results of quantitative strategic planning matrix method analysis was programmed in strategic position and action evaluation matrix. The present situation falls within "competitive" classification. This is indicative of weakness in coordinating development and environmental strategic plans. The result of present investigation strongly emphasis on compilation of strategic environmental plans for the control of population, pollution emission and land use planning changes. The most important strategies include development of environmental regulations and better supervision on enforcement of laws.
\end{abstract}

Key words: Caspian sea, human activities, coastal region, SWOT method, SPACE matrix

\section{INTRODUCTION}

Strategic planning is currently an extended tool for regional development and territorial structuring. Cities, regions and provinces have carried out their strategic plans on the basis of participation processes, which have driven the later development of their territories (Terrados, et al., 2005). Environmental analysis is a critical part of the strategic management planning process. The strengths, weaknesses, opportunities, and threats (SWOT) framework is proposed by many as an analytical tool which should be used to categorize significant environmental factors both internal and external to the organization (Pickton and Wright, 1998). In simple words, a coastal region is a site where ocean and sea comes together. It encompasses the coastal line environment and neighboring coastal waters. The constructing parts of this scope can include the following cases: coasts, coastal plains, coastal hills, coral reefs, marshes, river deltas, mangrove forests and

$\bar{\triangle} *$ Corresponding Author Email: arkarbassi738@yahoo.com Tel./Fax: +982161 113412 other coastal phenomena. According to the planning framework for integral management of coastal regions and rivers which was proposed by the UNEP in 1995 , river coasts and basins include very significant natural environments. However, they are severely affected by human activities. Both of these systems support a huge gamut of socio-economical activities (Mohammadizadeh, 2000). In other words, coastal regions ready the environment for purification and refining of industrial activities and also furnish appropriate ground for tourism industry development. In effect and from this viewpoint, the advantages of coastal environments become economically important. These regions are different in types of functions, forms and dynamics and one may not easily recognize the boundaries between them. The systems of coastal resources are natural and precious which should be managed for the sake of the present and the future generations. The coastal waters are environmentally very versatile and support a high percentage of oceanic life. However, 
most of coastal regions are international and inhabited by human beings (Ricketts and Harrison, 2007). The necessity to innovate some methods for management and protection of environment and marine resources has been broadly subjected to various investigations all over the world during 1950s. In the first conference of the national parks in 1962, preserving marine coastal regions was introduced as crucial issue. (Mohammadizadeh, 2000). In 1958, four conventions were issued regarding the marine rights under the title “Geneva Conventions”. These are as: 1) continental plateau convention, 2) high marine convention, 3) fishing conventions, and 4) live resources preservation in open seas in the oceans (Sharifipour, 2006). The integrated coastal zone management (ICZM) effectiveness study was undertaken between 1995 and 1997 to determine how well state coastal management programs in the United States were implementing five of the core objectives of the U.S. coastal zone management act (CZMA), (Hershman, et al., 2007; Khan, 1997). It seems that the first preserved coastalmarine region in probably the national Fort Jefferson in Florida in America with an area of 18850 ha. of seaboard and 35 ha. of coastal regions. Though this region was created in 1935, its existence as a preserved marine region was actually taken several years. The number of these regions in 69 countries reached 430 and also 298 regions were under consideration in 1985. Now, more than 120 countries have preserved coastal marine regions (IUCN, 1999), (Table 1). Coastal management aims at eliminating disputations and looks for adjusting the coastal activities with each other. However, coastal environment management looks after for coordination among at matching these activities with ground capabilities. It eliminates the disputations and via providing the actual layout and evaluating the feasibility. Coastal environment management aims at preserving and improving the coastal resources for an increasing world population which undergoes a growing continuous pressure (Salm and Clark, 1984). In environmental management planning, these procedures should be scrutinized and they should match different agents. The sociology scholars try to somehow consider a set of experiences of various societies in the regional planning, especially in natural resources prosperity and management. They also attempt to create a close relationship between the environmental managers and the regional planners The specialist and standard reports are the most precious management tools in the
Table 1: Distribution of the preserved coastal marine regions

\begin{tabular}{lc}
\hline Marine regions & $\begin{array}{c}\text { Number of preserved } \\
\text { coastal marine region }\end{array}$ \\
\hline South Pole & 23 \\
North Pole & 10 \\
Mediterranean & 46 \\
North-West Atlantic & 45 \\
North-East Atlantic & 34 \\
North Atlantic & 24 \\
Caribbean area & 76 \\
West Africa & 125 \\
South Atlantic & 25 \\
Indian Ocean & 25 \\
North Indian Ocean & 24 \\
South-East Africa & 9 \\
South-East Asia & 83 \\
South and Central Pacific Ocean & 49 \\
North-East Pacific Ocean & 54 \\
North-West Pacific Ocean & 201 \\
South-East Pacific Ocean & 25 \\
Australia & 304 \\
\hline Total & 1182 \\
\hline
\end{tabular}

development of local and regional groups and sectional approaches. This research attempts to conduct a system to offer optimum solutions for better management, knowing the present environment in the region. The goals of research include three priorities as follows: Identifying the destructive factors on the streamlet in Jouybar-Behshahr, a region where is located in the southern part of the Caspian Sea (Fig. 1). The study has been performed in the north of Iran, nearby the Caspian Sea in 2006-7, identifying strengths, opportunities, weaknesses and threats and finally providing the coastal environment management framework for the proposed region.

\section{MATERIALS AND METHODS}

The SWOT methodology leads to the obtainment of quantitative results useful in the first two phases of ICZM: in the first phase (initiation) an internal analysis is made through the calculation of environmental quality (strengths) and territory vulnerability (weaknesses) using environmental indicators. Then, an external analysis is made, through the analysis of threats and opportunities: Threats analysis is made by the use of qualitative and quantitative leopold matrixes that analyze the relation between human activities and natural environment; The opportunities evaluation and analysis is part of the planning phase of ICZM and it is represented by the numerical simulation of various projects on the territory to optimize numerically the results of strengths and threats: This type of numerical 


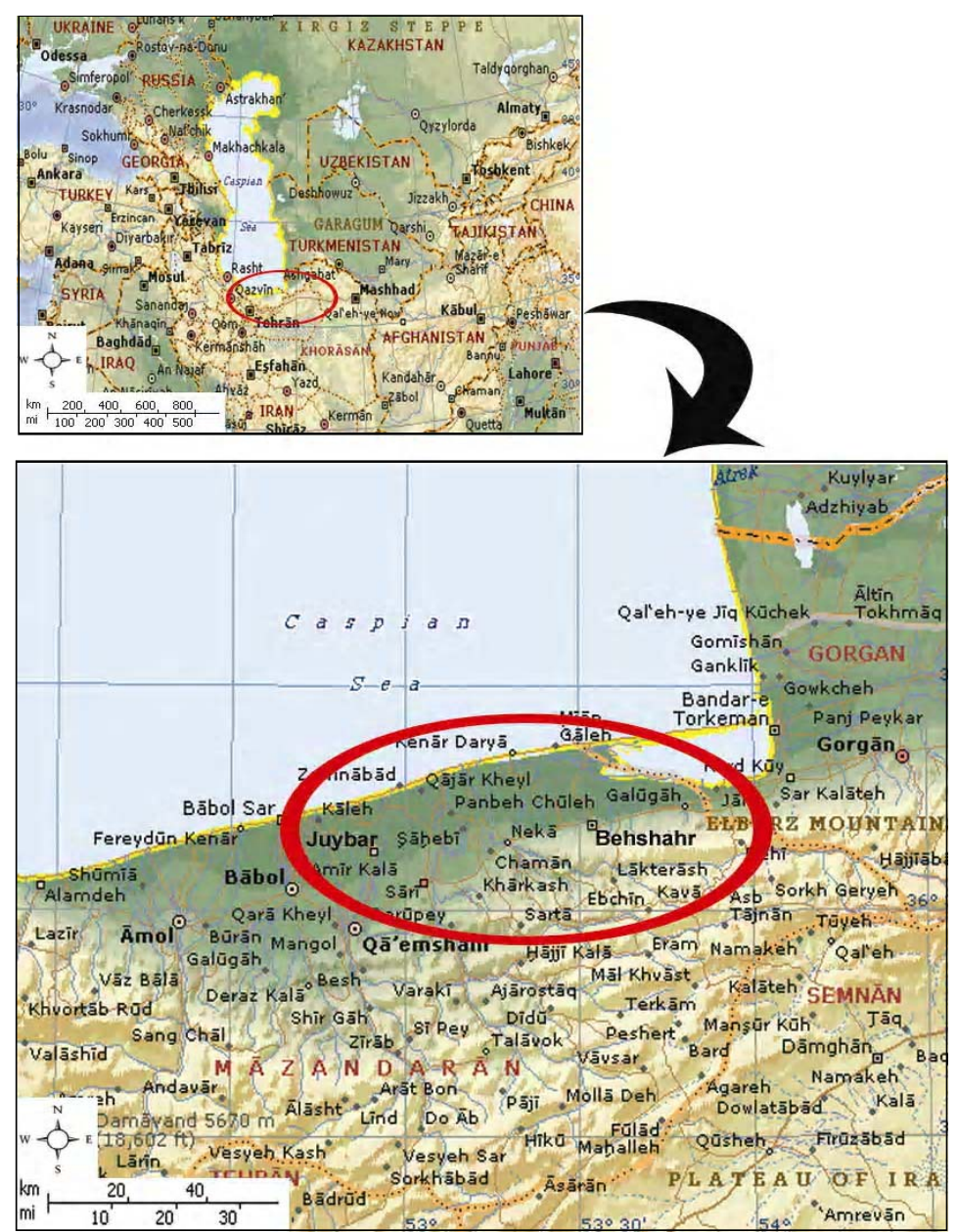

Fig. 1: Geographic location of the study area along the southern coast of the Caspian Sea, between Juybar and Behshahr regions

Table 2: stages of ICZM and SWOT analysis

\begin{tabular}{llll}
\hline ICZM stage & SWOT stage & System analysis & Evaluation tools \\
\hline \multirow{2}{*}{ Initiation } & Strengths (S) & Internal & Quality indicators \\
& Weaknesses (W) & Internal & Vulnerability indicators \\
& Threats (T) & External & Quantitative leopold matrixes \\
Planning & Opportunities (O) & External & $\begin{array}{l}\text { Change on environmental quality, decrease of } \\
\text { human impact } \\
\text { Management }\end{array}$ \\
\hline
\end{tabular}

analysis leads to a feedback process from the planning phase to tethe initiation phase: it is possible to calculate the variations of environmental quality (strengths) and of human interactions intensity (weaknesses) due to the simulation of various projects on the territory (opportunities), (Sanò and Fierro, 2003). Table 2 indicates the stages of ICZM and SWOT analyses. To manage and implement executive plans, initially available resources should be identified. Recognizing the sources is the first step in assessing and planning a land. Without recognizing the parameters relating to the land and marine resources, assessment and 
planning would be impossible. The region under study includes a part of the Caspian coasts in the Mazandaran province in the distances between the coasts of Jouybar and Behshahr which falls within latitude $52^{\circ} 80^{\prime}$ to $54^{\circ}$, and the longitude $36^{\circ} 45^{\prime}$ to $36^{\circ} 75^{\prime}$.

\section{Internal factors evaluation (IFE) matrix}

Internal factors consist of strengths and weaknesses. Many factors for strengths and weaknesses are determined. These factors are weighted in a way that the sum of these weighs is equal to one. Then, a score is allocated to each factor. These scores range between 1 and 4 . Score 1 denotes severe weakness, score 2 shows common weakness, score 3 indicates for a common strength and finally score 4 brings out important strengths. Therefore, there are a weight and a score for each factor. Once weight is multiplied by score, attractiveness of the factors can be assessed. If sum of all effective factors is less than 2.5, one can concludes that weaknesses are more than strengths. However, sums more than 2.5 indicate that strengths dominate over weaknesses.

\section{External factors evaluation (EFE) matrix}

External factors consist of opportunities and threats. In this regard, all the steps are similar to IFE matrix.

\section{Strategic position and action evaluation (SPACE) matrix}

Considering the factors of IFE and EFE matrix for aquaculture, variables that introduce "financial strengths (FS), competitive advantage (CA), environmental stability (ES) and industry strength (IS) are determined. IS and FS are scored between +1 (the worst) to +6 (the best). Then the mean of IS factor and the mean of FS factors are distinct on IS and FS axes. ES and CA are scored from -6 (the worst) to -1(the best). The mean of ES factors and the mean of CA factors are averaged on ES and CA axes. Furthermore, algebraic sum of values on the $X$ axes and algebraic sum of values on the $\mathrm{Y}$ axes are averaged. These two points determine the cartesian coordinate of position point. With zero point and position point, the diagram of position evaluation is drawn.

\section{Quantitative strategic planning matrix (QSPM)}

Witnessed judgment is used for quantitative strategic planning matrix. Determination of cumulative effects of each important internal and external factors can show the proportional attractiveness of each strategies. For presenting a quantitative strategic matrix, quadric factors (strength, weaknesses, opportunities and threats) from IFE and EFE matrixes are extracted. Allocated weight is written in the following column. Strategies are written in the first row. For score determination, internal and external factors that have a role in success are evaluated. A score from 1 to 4 is allocated to each factors. If a factor has not any important role in strategy selection process, it will not receive any score. This method considers collection of strategies simultaneously. With this matrix, infinite strategies can be evaluated. In the next step, sum of attractiveness of each strategy is computed. In this way, a collection of strategies can be considered simultaneously (Parsayan and Aarabi, 2004).

\section{RESULTS AND DISCUSSION}

SWOT analysis has been praised for its simplicity and practicality. As a framework, it has been widely adopted but, generally, its application has been accepted uncritically. It is timely to reappraise its value as a strategic management tool (Pickton and Wright, 1998). As Park and Farajzadeh, (2007) have mentioned, due to the different problems that exist in Iran's northern and southern coastal areas, different policies are considered for solving these problems. The policies for the Caspian Sea coastlines that are based on the strengths and weaknesses can be categorized as: 1 . equalization of distribution of population and activities along the coast consistent with the existing ecological capacities, 2. strengthening potential tourism capabilities and promoting its management efficiency at the national and international levels and giving priority to the private sector, 3. preventing irregular expansion of coastal cities and considering the shoreline's limitations for establishing new human settlements, 4. preventing marine environment pollution, prevention of forest destruction, protection of soil-water resources and enhancing shoreline ecotourism via strengthening environmental management. Water pollution in the rivers flowing into the Caspian Sea is slowly detroiting its highly sensitive marine life (Karbassi, et al., a: in press and Karbassi, et al., b: in press). Scientists estimate that each year about of 60,000 metric tons of petroleum byproducts, 24,000 tons of sulfites and 400,000 tons of chlorine are discharged into the Caspian Sea (Aghai, 2003; Nadim, 
Int. J. Environ. Sci. Tech., 5 (1), 43-52, Winter 2008

Table 3: Evaluation of external factors

\begin{tabular}{|c|c|c|c|c|}
\hline No. & External factors & Weight & Score & Attractiveness \\
\hline \multicolumn{5}{|c|}{ Opportunities } \\
\hline 2 & $\mathrm{O}_{2}$ : Legal preparations for collecting environmental penalties & 0.08 & 3 & 0.24 \\
\hline 4 & $\mathrm{O}_{4}$ : Possibility of installing and starting-up systems for collecting and treating sewages. & 0.04 & 4 & 0.16 \\
\hline 5 & $\mathrm{O}_{5}$ : Preparing the essential backgrounds to teach people about environmental issues. & 0.05 & 3 & 0.15 \\
\hline 6 & $\mathrm{O}_{6}$ : Possibility to categorize coastal areas with regard to tourists and type of usage. & 0.03 & 3 & 0.09 \\
\hline 9 & $\mathrm{O}_{9}$ : Possibility of enhancing and reviewing environmental regulations and supervisions. & 0.1 & 3 & 0.3 \\
\hline \multicolumn{5}{|c|}{ Threats } \\
\hline 10 & $* \mathrm{~T}_{1}$ : Discharge of un-treated human wastes and industrial ones in to environment. & 0.1 & 1 & 0.1 \\
\hline 15 & $\mathrm{~T}_{6}$ : High ground water tables. & 0.05 & 2 & 0.1 \\
\hline 16 & $\mathrm{~T}_{7}$ : High soil erosion. & 0.05 & 2 & 0.1 \\
\hline 17 & $\begin{array}{l}T_{8} \text { : Extraordinary concentration of industries in the province compared to other regions } \\
\text { of the country. }\end{array}$ & 0.06 & 2 & 0.12 \\
\hline \multirow[t]{2}{*}{18} & $\mathrm{~T}_{9}$ : Incremental pollution due to flood rivers. & 0.03 & 1 & 0.03 \\
\hline & & 1 & & 2.52 \\
\hline
\end{tabular}

* O: Opportunities; $\quad \mathrm{T}$ : Threats

Table 4: Evaluation of internal factors

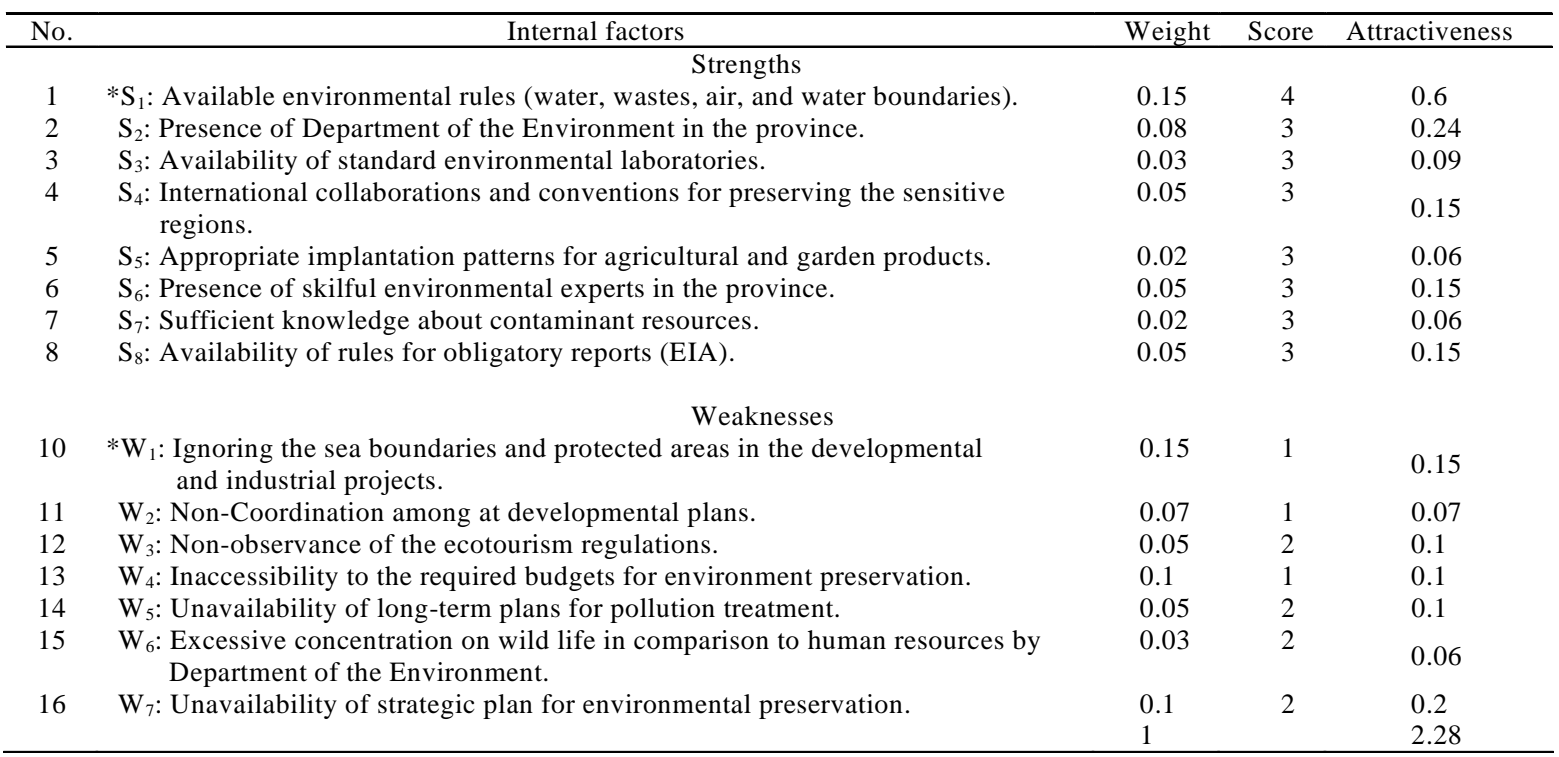

* S: Strengths; W: Weaknesses

et al., 2006), 5. expansion of fishing ports, fishing fleet, fishing industries and increasing the aquaculture production and export, 6. development and equipment of marine terminals and ports and providing required facilities to meet with the increasing demand for cargo transit, 7. land allocation consistent with coastal environment's potentials and capabilities and 8 . appropriate utilization of soil water resources to increase quality of agricultural products. Hakanson and Blenckner (in press) reported that for coastal management, it is important to defining permissible ranges (lower and upper values), thresholds and points of no return for all bioindicators. This should be done to minimize risks related to changes in ecosystem 
Table 5: SWOT matrix: Derivation of the key strategies in the coastal management in the region

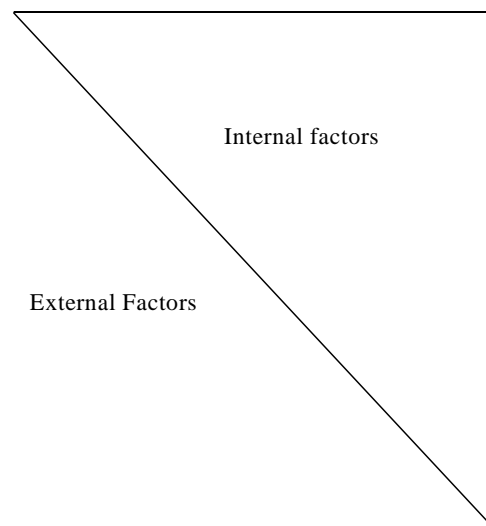

1) Opportunities (O)

$\mathrm{O}_{1}$ : Tourism attractions environmental penalties

$\mathrm{O}_{3}$ : Preparing the ground to limit the accessibility to sensitive sites.

$\mathrm{O}_{4}$ : Possibility of installing and starting-up systems for collecting and treating sewages.

$\mathrm{O}_{5}$ : Preparing the essential backgrounds to teach people about environmental issues.

$\mathrm{O}_{6}$ : Possibility to categorize coastal areas with regard to tourists and type of usage.

$\mathrm{O}_{7}$ : Receiving tourist costs and its allocation to promote the environmental quality.

$\mathrm{O}_{8}$ : Possibility of providing fund as environmental loans to minimize

$\mathrm{O}_{9}$ : Possibility of enhancing and reviewing environmental regulations and supervisions.
$\mathrm{O}_{2}$ : Legal preparations for collecting environmental problems.

3) Strengths (S)

$\mathrm{S}_{1}$ : Available environmental rules (water, wastes, air, and water boundaries)

$\mathrm{S}_{2}$ : Presence of Department of the Environment in the province.

$\mathrm{S}_{3}$ : Availability of standard environmental laboratories

$\mathrm{S}_{4}$ : International collaborations and conventions for preserving the sensitive regions.

$\mathrm{S}_{5}$ : Appropriate implantation patterns for agricultural and garden products.

$\mathrm{S}_{6}$ : Presence of skilful environmental experts in the province

$\mathrm{S}_{7}$ : Sufficient knowledge about contaminant resources (EIA)

Strategies on the basis of strength points and opportunities (SO)

- Enactment of environmental laws to promote reception of the penalties, and applying more limitations

- Increasing supervision on execution of environmental regulations to exactly enact the laws and enhance the present situations- Use of the capabilities of private laboratories to determine contamination amount for assessing the penalties

- Using the experiences and facilities of

international organizations in categorizing the coasts, enhancing the monetary fund supporting the environment and methods of implementing the environmental penalties

- Providing an information data bank about the amount and the type of contaminants to offer scientific-operational methods to reduce their environmental effects

- More effective use of EIA reports to identify and categorize the sensitive coastal regions and offering the environmental education to local communities and industry owners.

The strategies on the basis of the strength points and threats (ST)

$\mathrm{T}_{1}$ : Discharge of un-treated human wastes and industrial ones in to environment.

$\mathrm{T}_{2}$ : Unavailability of central system for collecting litters.

$\mathrm{T}_{3}$ : Excessive consumption of agricultural pesticides and fertilizers

$\mathrm{T}_{4}$ : Congested population per each square $\mathrm{km}$.

$\mathrm{T}_{5}$ : Land use change.

$\mathrm{T}_{6}$ : High ground water tables.

$\mathrm{T}_{7}$ : High soil erosion.

$\mathrm{T}_{8}$ : Extraordinary concentration of industries in the province compared to other regions of the country.

$\mathrm{T}_{9}$ : Incremental pollution due to flood rivers.

- Precise enactment of environmental rules to act against pollution centers producing

- Effective use of environmental rules to avoid excessive concentration of industries in specific area

- Environmental supervisions to prevent

discharge of contaminants all around the flooding rivers

- Limiting the installation of industries on the basis of types of contaminant combinations

- Determining the amount of required treatment of urban and industrial wastes on the basis of the type of contaminants

- Applying the patterns of garden and agricultural implementation to reduce the consumption of pesticides, to avoid soil erosion, to change the
$\mathrm{S}_{8}$ : Availability of rules for obligatory reports

4) Weaknesses (W)

$\mathrm{W}_{1}$ : Ignoring the sea boundaries and protected areas in the developmental and industrial projects.

$\mathrm{W}_{2}$ : Non-coordination among at developmental plans.

$\mathrm{W}_{3}$ : Non-observance of the ecotourism regulations.

$\mathrm{W}_{4}$ : Inaccessibility to the required budgets for environment preservation.

$\mathrm{W}_{5}$ : Unavailability of long-term plans for pollution treatment.

$\mathrm{W}_{6}$ : Excessive concentration on wild life in comparison to human resources by Department of the Environment.

$\mathrm{W}_{7}$ : Unavailability of strategic plan for environmental preservation.

Strategies on the basis of the strength points and opportunities (WO)

- Using the potential of the tourism attractions to accelerate establishing the strategic environmental system and applying ecotourism regulations

- Considering environmental penalties to provide the required budgets for environment preservation

- Enacting and supervising the observation of guidelines for considering environmental boundaries

- Categorizing the coasts to observe the environmental boundaries

- Effective enforcement of ecotourism regulations

- Providing the required budgets for environment preservation via enforcing and receiving the tourism costs

- Providing and starting up monetary funds to over- come budget problems

- Revising the rules and regulations specific to coastal regions to match the developmental plans and promoting the coastal environment situation

- Revising the rules and regulations specific to the coastal environment for more effective observation of ecotourism regulations.

The strategies on the basis of the weak points and threats (WT) lands functions, and to reduce the contamination of the underground water.
- Preparing strategic environmental plans to control the population intensity, contamination distribution and change in the lands uses

- Dividing the supervision capabilities on the part of the Department of the Environment to balance the required controls in the section relating to human environment compared with wild life

- Preparing long-term monitoring plans for recognizing the conditions of the pollutions

- Enhancing the environmental budgets to control pollution

- Issuing ecotourism regulations to limit the discharge of the contaminants

- Coordination among at the developmental plans to promote the quality of the coastal environment

- Observing the environmental boundaries to limit the distribution. 
Table 6: Priorities of the executive strategies for managing the coastal regions between Jouybar and Behshahr

\begin{tabular}{|c|c|c|c|}
\hline No. & Strategy & Rate & $\%$ \\
\hline 1 & $\begin{array}{l}\mathrm{ST}_{21} \text { : Strategic environmental planning to control the population concentration, pollution } \\
\text { distribution, and land use planning }\end{array}$ & 6.88 & $5.92 \%$ \\
\hline 2 & $\mathrm{ST}_{23}$ : Long-term monitoring programs to recognize the pollution conditions & 5.55 & $4.77 \%$ \\
\hline 3 & $\begin{array}{l}\mathrm{ST}_{5} \text { : Preparing a data bank about the amount and type of contaminants to offer the scientific- } \\
\text { operational methods for reducing their environmental effects }\end{array}$ & 5.51 & $4.74 \%$ \\
\hline 4 & $\begin{array}{l}\mathrm{ST}_{2} \text { : Increasing the supervision of the environmental law execution to exactly enforce the law } \\
\text { and improve the present situation }\end{array}$ & 5.50 & $4.73 \%$ \\
\hline 5 & $\begin{array}{l}\mathrm{ST}_{1} \text { : Enactment implementation of rules to promote the financial penalties and applying more } \\
\text { limitations }\end{array}$ & 5.36 & $4.61 \%$ \\
\hline 6 & $\mathrm{ST}_{8}$ : Effective application of rules to avoid excessive concentration of industries in one region & 5.35 & $4.60 \%$ \\
\hline 7 & $\begin{array}{l}\mathrm{ST}_{27} \text { : Observance of environmental boundaries on the basis of the type of contaminant } \\
\text { combinations }\end{array}$ & 5.28 & $4.54 \%$ \\
\hline 8 & $\mathrm{ST}_{10}$ : Limiting the establishment of industries on the basis of types of contaminant combinations & 5.11 & $4.39 \%$ \\
\hline 9 & $\mathrm{ST}_{24}$ : Raising the environmental budgets to control the pollution & 4.97 & $4.27 \%$ \\
\hline 10 & $\begin{array}{l}\mathrm{ST}_{14} \text { : Using the environmental financial penalties to provide the required budgets for } \\
\text { environment preservation }\end{array}$ & 4.92 & $4.23 \%$ \\
\hline 11 & $\mathrm{ST}_{7}$ : Exact enforcement of environmental rules to act against pollution of producing centers & 4.86 & $4.18 \%$ \\
\hline 12 & $\mathrm{ST}_{9}$ : Environmental supervision to avoid pollution evacuation around the flooding rivers & 4.84 & $4.16 \%$ \\
\hline 13 & $\begin{array}{l}\mathrm{ST}_{4} \text { : Using the possibilities and experiences of the international organizations in categorizing the } \\
\text { coasts, enhancing the financial resources for supporting environment, and executing the } \\
\text { environmental penalties }\end{array}$ & 4.79 & $4.12 \%$ \\
\hline 14 & $\begin{array}{l}\mathrm{ST}_{22} \text { : Dividing the supervision capabilities of the Department of the Environment to balance the } \\
\text { required control of the human environment compared to wild life }\end{array}$ & 4.57 & $3.93 \%$ \\
\hline 15 & $\begin{array}{l}\mathrm{ST}_{6} \text { : Take more effective results out of EIA reports to identify and categorize the sensitive } \\
\text { coastal regions and offering the environmental training to local communities and the }\end{array}$ & & \\
\hline & industrial owners & 4.56 & $3.92 \%$ \\
\hline 16 & $\mathrm{ST}_{26}$ : Matching the developmental plans to promote the quality of coastal environment & 4.42 & $3.80 \%$ \\
\hline 17 & $\mathrm{ST}_{25}$ : Enacting ecotourism regulations to limit the development of contaminants & 4.02 & $3.46 \%$ \\
\hline 18 & $\begin{array}{l}\mathrm{ST}_{11} \text { : Determining the amount of the required treatment of urban and industrial wastes on the } \\
\text { basis of the types of contaminants }\end{array}$ & 3.63 & $3.12 \%$ \\
\hline 19 & $\begin{array}{l}\mathrm{ST}_{12} \text { : Applying the patterns of garden and agricultural implementation to reduce the consumption } \\
\text { of pesticides, to avoid soil erosion, to change the lands functions, and to reduce the } \\
\text { contamination of the underground waters }\end{array}$ & 3.63 & $3.12 \%$ \\
\hline 20 & $\begin{array}{l}\mathrm{ST}_{13} \text { : Using the potential for tourism attraction to accelerate establishing the strategic } \\
\text { environmental system and applying ecotourism regulations }\end{array}$ & 3.58 & $3.08 \%$ \\
\hline 21 & $\begin{array}{l}\mathrm{ST}_{15} \text { : Enacting and supervising the observance of guidelines for considering environmental } \\
\text { boundaries }\end{array}$ & 3.57 & $3.07 \%$ \\
\hline 22 & $\begin{array}{l}\mathrm{ST}_{3} \text { : Making use of the capabilities of private laboratories to determine contamination amount } \\
\text { for assessing the penalties }\end{array}$ & 3.54 & $3.04 \%$ \\
\hline 23 & $\mathrm{ST}_{18}$ : Providing and starting up monetary funds to overcome budget problems & 2.79 & $2.40 \%$ \\
\hline 24 & $\begin{array}{l}\mathrm{ST}_{16} \text { : Categorizing the coasts to observe the environmental boundaries. Effective execution of } \\
\text { ecotourism regulations }\end{array}$ & 2.37 & $2.04 \%$ \\
\hline 25 & $\begin{array}{l}\mathrm{ST}_{17} \text { : Providing the required budgets for environmental preservation via determining and } \\
\text { receiving the tourism costs }\end{array}$ & 2.32 & $1.99 \%$ \\
\hline 26 & $\begin{array}{l}\mathrm{ST}_{20} \text { : Revising the rules and regulations specific to the coastal regions for better observance of } \\
\text { ecotourism regulations. }\end{array}$ & $\begin{array}{c}2.28 \\
\Sigma=100 \%\end{array}$ & $\begin{array}{r}1.96 \% \\
\Sigma_{116.6}\end{array}$ \\
\hline
\end{tabular}


Environmental management of coastal regions...

Table 7: SPACE matrix; the matrix for evaluating situations and strategic measures

\begin{tabular}{|c|c|}
\hline Items & Score \\
\hline \multicolumn{2}{|l|}{ Financial Status (FS) } \\
\hline 1. There is no legal backgrounds for receiving the environmental penalties & +4 \\
\hline 2. Receiving the tourism penalties and in allocation for the promotion of environmental quality & +6 \\
\hline 3. Providing financial resources for environment preservation & $\begin{array}{c}+5 \\
15: 3=5\end{array}$ \\
\hline \multicolumn{2}{|l|}{ Industrial Status (IS) } \\
\hline 1. Feasibility of categorizing the coastal regions regarding the tourists returns and the usage type & +3 \\
\hline 2. Possibility of enhancing and reviewing the regulations and environmental supervision specific to coastal regions & +3 \\
\hline 3. Tourism attractions & +6 \\
\hline 4. Making use of international collaborations & +4 \\
\hline 5. Environmental rules & $\begin{array}{c}+4 \\
20: 5=4\end{array}$ \\
\hline \multicolumn{2}{|l|}{ Environmental Stability (ES) } \\
\hline 1. Ignoring the environmental boundaries & -4 \\
\hline 2. Excessive concentration of industries in the province comparing to other regions in the country & -6 \\
\hline 3. High water surface & -2 \\
\hline 4. Presence of flood rivers & $\begin{array}{c}-1 \\
-13: 2=-6.5\end{array}$ \\
\hline Competitive Advantage (CA) & \\
\hline 1. Unavailability of strategic environmental plans & -6 \\
\hline 2. There is not any coordination among at the developmental plans & $\begin{array}{c}-6 \\
-12: 2=-6\end{array}$ \\
\hline
\end{tabular}

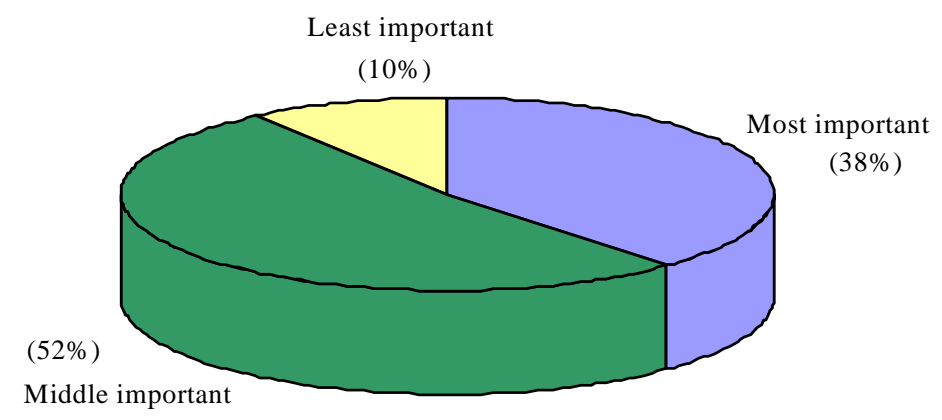

Fig. 2: The importance of strategies from the most to the least important

structure and biodiversity and keeping an open dialogue between scientists, policy makers, administrators and the general public based on facts and reason rather than feelings and emotions, which are ingredients in many "environmental" debates and discussions. In the Tables 2 and 3, the external elements and the internal factor matrix along with the relative coefficient and scores are presented. As it can be concluded from the results of (Table 4) the sum of the internal factors equals 2.28 which is evident of dominance of weaknesses over the strengths in the area of study. Moreover, the sum of the coefficients in Table 3 equals 2.52 that indicates opportunities and the threats are present in the region. In addition to relationship among strengths, weaknesses, opportunities and threats, the possible strategies were identified. The concluding results are clearly presented in Table 5. From a theoretical point of view, QSPM can reveal strategies. In other words, QSPM can determine the quality of strategy that can successfully use the internal and external effective factors. The associative effects of each one of such internal and external effective factors could determine the relative interaction of each strategy within the application strategy aggregate. Finally by applying appropriate scores and coefficients, strategies were set in accordance to their attractiveness (Table 6). After arrangements of the strategies by their importance, they were categorized into three groups: important, average and weak. Table 6 manifests such categorization. According to Table 6, it is apparent that about $40 \%$ of the strategies is considered as the important strategies, $50 \%$ of them is 


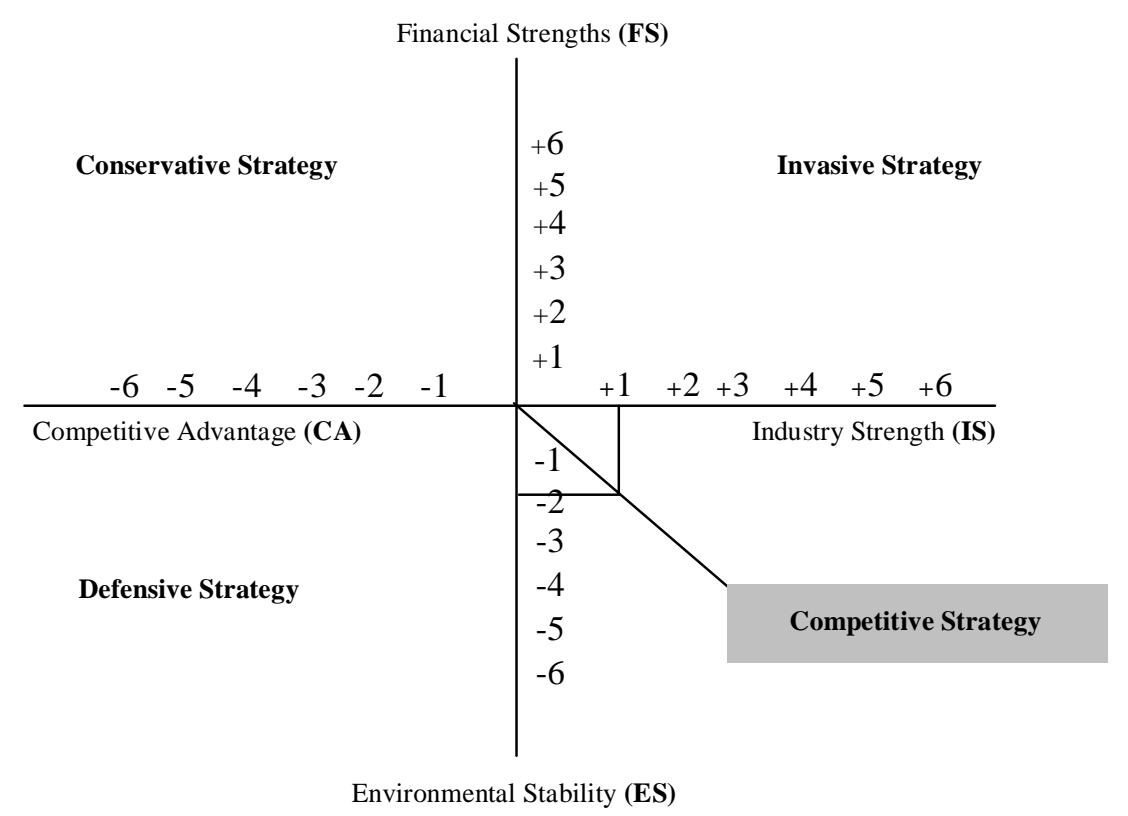

Fig. 3: Position evaluation diagram of SPACE matrix

regarded as average strategies, and the remaining 10\% is among the weak strategies (Fig. 2). Now, the organization can apply and implement the environmental management strategies in the region, using this prioritization on the basis of time and location. As mentioned in the materials and methods first of all, the four variables of FS, CA, ES and IS are determined and rated (Table 7). When there is a vector in the matrix invasive position, the organization stands in the possible best status and can take the following measures through using the internal capabilities or strengths: 1 . to use internal opportunities, 2. to remove internal weaknesses and 3 . to avoid external threats. If the vector stands in the conservative position, it means that organization should preserve its own merits and avoid exposure to high risks. If the vector settles in the defensive position, it means that the internal weak points should be amended and external threats should be avoided. However according to Fig. 3, the position of region does not fall in to the 3 above mentioned zones. The situation of the region under study is using a competitive strategy. This means that special attention must be paid to the competitive strategies, i.e. expressing the strategic environmental planning and matching the plans for development. It should be pointed out that strategic environmental assessment (SEA) is not a common practice in developing countries including Iran. Thus, development of strategies is considered periodically. Under such situation, the SWOT analysis should be carried out from time to time to meet with new situations. In the present investigation, proper strategies were developed using the SWOT method. These strategies cover wide range of policies that should be implemented at a shorter time. The present study also showed that more clear coordination is needed among various organizations.

\section{ACKNOWLEDGEMENTS}

The authors would like to express their sincere appreciation for the Organizations and Departments in Iran which cooperate in this research, such as Management and Planning Organization; JihadAgriculture Ministry as well as the Caspian Sea local authorities. Moreover, sincere thanks to Miss. Jalalvandi for her translation assistance throughout the article text.

\section{REFERENCES}

Aghai, D. B., (2003). Pollution in the Caspian Sea, Payvand Iran News, available at http://www.payvand.com/news/02/ jul/1073.html

Hakanson, L.; Blenckner, T., (in press). A review on operational bioindicators for sustainable coastal management-criteria, motives and relationships. Ocean and Coastal Management. Elsevier Publisher. 
Hershman, M. J.; Good, J. W.; Bernd-Cohen, T.; Goodwin, R. F.; Lee, V.; Pogue, P., (2007). The effectiveness of coastal zone management in the United States. Coast. Manage., 27 (2), 113-138.

IUCN (1999). Guidelines for marine protected areas. Edited and coordinated by G. R. A. Eme 7 K. Green. The World Conservation Union.

Karbassi, A. R.; Nouri, J.; Ayaz, G. O., (in press: a). Behavior of $\mathrm{Cu}, \mathrm{Zn}, \mathrm{Pb}, \mathrm{Ni}$ and $\mathrm{Mn}$ during mixing of $\mathrm{Cu}, \mathrm{Zn}, \mathrm{Pb}, \mathrm{Ni}$ and $\mathrm{Mn}$ during mixing of freshwater. Desalination, Elsevier Publisher.

Karbassi, A. R.; Nouri, J.; Mehrdadi, N.; Ayaz, G. O., (in press: b). Flocculation of heavy metals during mixing of freshwater with Caspian Sea water. Environ. Geo., SpringerLink Publisher.

Khan, N. Y., (1997). Role of environmental impact assessment in integrated coastal zone management, in coastal zone management imperatives for maritime developing nations, Kluwer Academic Publishers.

Mohammadizadeh, M., (2000), Environmental Management of south coast of Caspian sea Organization and administration perspectives, M.Sc. thesis, in environmental management, Science and Research Campus, IAU, Tehran, Iran.

Nadim F.; Bagtzoglou A. C.; Iranmahboob J., (2006). Management of coastal areas in the Caspian Sea region: Environmental issues and political challenges. Coast. Manage., 34, 153-165.
Park, A.; Farajzadeh, M., (2007). Iran's integrated coastal management plan: Persian Gulf, Oman Sea, and southern Caspian Sea coastlines. Ocean Coast. Manage., 50 (9), 754-773.

Parsayan, A.; Aarabi, M., (2004). Strategic management, $6^{\text {th. }}$ Ed. Cultural Studies Office, Tehran, Iran.

Pickton, W. D.; Wright, S., (1998). What's SWOT in strategic analysis?, Strategic Change, 7(2), 101-109.

Ricketts, P.; Harrison, P., (2007). Coastal and ocean management in Canada: moving into the $21^{\text {st }}$ Century. Coast. Manage., 35, 5-22.

Salm, R. V.; Clark, J. R., (1984). Marine and coastal protected areas: A guide for planners and managers. IUCN, Gland, Switzerland.

Sanò, M.; Fierro, G., (2003). Integration of the SWOT analysis as a coastal management tool with a geographical information system: Two approaches to the problem and first results Dipartimento per lo studio del Territorio e delle sue Risorse (Dip.Te.Ris.) Università di Genova (IT), University of Georgia.

Sharifipour, R., (2006). Environmental sensitivity of Bushehr province coastline in regard with pollutand hazardous, Ph.D. thesis, Science and Research Campus, IAU, Tehran, Iran.

Terrados, J.; Almonacidand, G.; Hontoria, L., (2005). Regional energy planning through SWOT analysis and strategic planning tools. Impact on renewables development. Renew. Sust. Energ. Rev., 11 (6), 1275-1287.

UNEP (1995). Guidelines for integrated management of coastal and marine areas. United Nations Environment Programe.

\section{AUTHOR (S) BIOSKETCHES}

Nouri, J., Ph.D., Professor, Department of Environmental Management, Graduate School of the Environment and Energy, Science and Research Campus, IAU, Tehran, Iran. Email: nourijafar@gmail.com

Karbassi, A. R., Ph.D., Assistante professor, Graduate Faculty of the Environment, University of Tehran, Tehran, Iran. Email: arkarbassi738@yahoo.com

Mirkia, S., M.Sc., Department of Environmental Management, Graduate School of the Environment and Energy, Science and Research Campus, IAU, Tehran, Iran. Email: samareh.mirkia@gmail.com

This article should be referenced as follows:

Nouri, J.; Karbassi, A. R.; Mirkia, S., (2008). Environmental management of coastal regions in the Caspian Sea. Int. J. Environ. Sci. Tech., 5(1), 43-52. 